\title{
CARBON DIOXIDE AND MONOXIDE ABOVE THE TROPOSPHERE
}

\author{
P. B. HAYS and J. J. OLTVERO* \\ Department of Aerospace Engineering, Aeronomy Program, \\ University of Michigan, Ann Arbor, Mich. 48105, U.S.A.
}

(Received in final form $26 \mathrm{May} 1970$ )

\begin{abstract}
The dependence of the atmospheric distributions of $\mathrm{CO}_{2}$ and $\mathrm{CO}$ upon the combined effects of photochemical production and loss, and transport is examined. It is found that, for $\mathrm{CO}_{2}$, deviations from complete mixing are possible in the mesosphere and upper stratosphere. Further, sufficient quantities of $\mathrm{CO}$ may be maintained, as a product of $\mathrm{CO}_{2}$ photodissociation, to be aeronomically significant.
\end{abstract}

The role of carbon dioxide as a major participant in the transfer of infrared radiation through the Earth's atmosphere has been apparent for many years (Gold, 1909). Moreover, both the recent suggestion of using the $4 \cdot 3 \mu$ and $15 \mu$ bands of $\mathrm{CO}_{2}$ as means by which to measure remotely atmospheric temperature (Kaplan, 1959), and the recognition of the role played by $\mathrm{CO}_{2}$ in the thermal budget of the mesosphere (Curtis and Goody, 1956) have greatly increased our understanding of its importance. Ultimately, the accuracy of such studies must depend upon a knowledge of the distribution of $\mathrm{CO}_{2}$ in the upper atmosphere. This discussion briefly considers the factors which influence the distribution of $\mathrm{CO}_{2}$ in the stratosphere, mesosphere, and lower thermosphere.

Carbon monoxide has been measured at concentrations of between 0.1 and $0.2 \mathrm{ppm}$ in the troposphere (Robinson and Robbins, 1967). Thought to be chiefly the product of automobile exhausts, it has become a major air pollutant in this century, Little is known of its abundance in the upper atmosphere and the proximity of its molecular mass to that of $\mathrm{N}_{2}$ precludes mass spectrometric identification.

Carbon dioxide is continuously produced at or near the Earth's surface by combustion and biological decay, and is also released from the oceans (Robinson and Robbins, 1967). Turbulent mixing within the troposphere should be sufficiently rapid that complete mixing is a valid assumption. In the past it has been assumed that this is true for the stratosphere, mesosphere, and lower thermosphere as well. However, in both the mesosphere and thermosphere $\mathrm{CO}_{2}$ is dissociated and/or ionized by solar (u.v.) radiation. Thus, either a vertical flux must be maintained or the resulting $\mathrm{CO}$ must recombine locally in order to balance this loss. Recombination is thought to occur both by the three body process:

$$
\mathrm{CO}+\mathrm{O}+\mathrm{M} \rightarrow \mathrm{CO}_{2}+\mathrm{M}
$$

$$
K_{a}=10^{-34} \mathrm{~cm}^{6} / \mathrm{sec} \text { at } 300^{\circ} \mathrm{K}
$$

(Kaufman, 1968).

and by the two body process:

$$
\mathrm{CO}+\mathrm{OH} \rightarrow \mathrm{CO}_{2}+\mathrm{H}
$$

$$
K_{b}=1.5 \times 10^{-13} \mathrm{~cm}^{3} / \mathrm{sec} \text { at } 300^{\circ} \mathrm{K}
$$

(Kaufman, 1968).

Estimates of process (a) suggest a significant effect on the vertical flux below about $60 \mathrm{~km}$. The effect of process (b) is much less clear due to the present state of uncertainty in the $\mathrm{OH}$ distribution. Using the time constants for transport and recombination as a basis for comparison, and assuming an $\mathrm{OH}$ concentration as large as given by Hesstvedt (1967), as an upper limit, one finds that above $70 \mathrm{~km}$ transport dominates but local photochemical equilibrium will prevail below that level. Because of the uncertainties the following

*On leave from NASA-Langley Research Center. 
two limiting cases were considered: (1) no recombination; and (2) full recombination of $\mathrm{CO}$ below $70 \mathrm{~km}$ and none above. These cases should encompass the possible variations of $\mathrm{CO}_{2}$ and $\mathrm{CO}$ in the atmosphere.

The general method employed here in calculating the distributions of $\mathrm{CO}_{2}$ and $\mathrm{CO}$ is similar to that used by Colegrove, Hanson and Johnson $(1965,1966)$, where both molecular and eddy diffusion as well as photochemical production and loss are considered. It is found that the problem can be simplified by introducing a parameter, $\zeta$, which equals the ratio of the actual mixing ratio of a species to that for the zero flux case. A brief discussion of the formulation is contained in the Appendix.

The dissociation rate for $\mathrm{CO}_{2}$ used in these calculations is a global average obtained from $\mathrm{CO}_{2}$ cross sections as listed in Table 1, with values for solar u.v. flux and total absorption cross sections taken from Hinteregger, Hall, and Schmidtke (1965). An atmospheric model essentially the same as the CIRA-1965 model is used.

TABLE 1. SOURCES OP CARBON DIOXIDE CROSS SECTIONS

\begin{tabular}{cl}
\hline \multicolumn{1}{c}{ Wavelength } & \multicolumn{1}{c}{ Reference } \\
\hline $165-580 \AA\left(\begin{array}{c}\text { except } 303.8 \AA \\
\text { solar line }\end{array}\right)$ & Romand $(1966)$ \\
Solar lines: $\begin{array}{l}303.8 \AA, 765 \cdot 1 \AA, \\
708.7 \AA, \text { etc. }\end{array}$ & Cairns and Samson (1965) \\
$580-1675 \AA\left(\begin{array}{c}\text { except solar } \\
\text { lines }\end{array}\right)$ & $\begin{array}{l}\text { Nakata, Watanabe and Matsunaga } \\
\text { (1965) } \\
1675-1775 \AA\end{array}$ \\
& $\begin{array}{l}\text { Thompson, Harteck and Reeves } \\
(1963)\end{array}$ \\
\hline
\end{tabular}

The molecular diffusion coefficients for $\mathrm{CO}_{2}$ and $\mathrm{CO}$ were taken from Chapman and Cowling (1939) and Lettau (1951). The eddy diffusion coefficients, $K_{T}$, used in this study fall naturally into the categories of stratospheric and upper atmospheric values. In the stratosphere, the maximum, minimum and global averages of the seasonal-latitudinal values of $K_{T}$, given by Gudiksen et al. (1968) were adopted. These three mixing profiles were extrapolated from 27 to $50 \mathrm{~km}$. to match the upper atmospheric value; they are shown in Fig. 1, labelled $C, D$ and $E$. Between 50 and $120 \mathrm{~km}$ an equilibrium eddy diffusion coefficient was determined from an earth-averaged thermal model (Olivero, 1970) in a manner similar to Johnson and Wilkins (1965) and Johnson (1968). Above $120 \mathrm{~km} K_{T}$ was allowed to decrease exponentially. The eddy diffusion profile adopted as well as the range of values associated with the uncertainties in the inputs to the thermal model are shown in Fig. 1. Thus three models of eddy diffusion were chosen and used in all calculations corresponding to maximum, minimum and average mixing in the stratosphere and average mixing above $50 \mathrm{~km}$.

The time independent continuity equation was integrated between the tropopause $(12 \mathrm{~km})$ and $200 \mathrm{~km}$ for each of the combinations of the three eddy diffusion profiles and two characterizations of recombination. The $\mathrm{CO}_{2}$ volume mixing ratio was set at $3.145 \times 10^{-4}$, the average sea level value (Bolin and Keeling, 1963) at the tropopause and the CO volume mixing ratio was set at $1 \times 10^{-7}$ (Robinson and Robbins, 1967) at the tropopause.

The results of the calculations for $\mathrm{CO}_{2}$ and $\mathrm{CO}$ are shown in Fig. 2. It is apparent that the question of recombination is not significant for $\mathrm{CO}_{2}$ within the limits of eddy diffusion considered. On the other hand, the $\mathrm{CO}$ mixing ratio is critically dependent upon 




FIG. 1. EDDY DIFFUSION CORFFICIENTS USED ALONG WITH OTHER ESTIMATES.

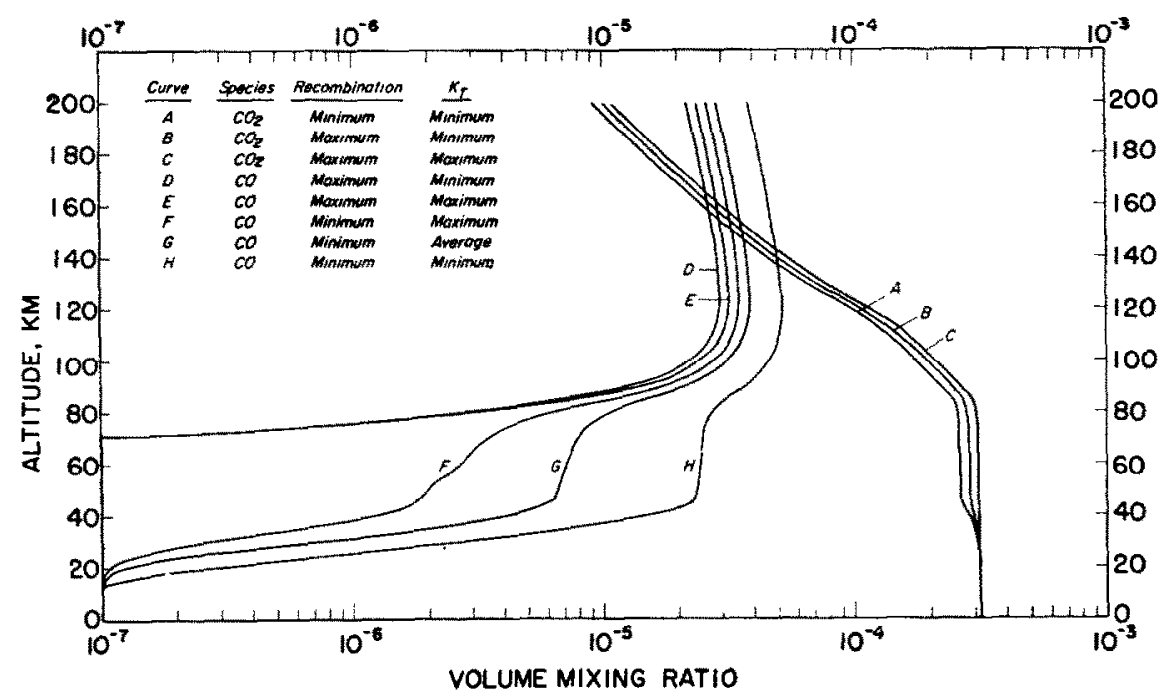

Fig. 2. Calculated profiles of the volume mixing ratios of $\mathrm{CO}_{2}$ and $\mathrm{CO}$.

recombination. The limits of eddy diffusion and recombination used in these calculations lead to more than two orders of magnitude uncertainty in the $\mathrm{CO}$ mixing ratio in the upper stratosphere and lower mesosphere. However, in the thermosphere the uncertainty is reduced to less than a factor of two, and $\mathrm{CO}$ is shown to be a significant minor constituent. Because of the importance of these results to aeronomical studies confirming experimental evidence would be highly desirable. 
Any measurement of $\mathrm{CO}$ in our atmosphere will be quite difficult in practice to accomplish. One might observe the Cameron or the fourth positive bands which arise from transitions to the ${ }_{a}^{\mathbf{3}} \pi$ and ${ }_{a}^{1} \pi$ levels respectively. But these transitions are either forbidden or hidden by nitric oxide and molecular oxygen bands in the same region of the spectrum. However, if actual measurements of the carbon monoxide concentration in the mesosphere and thermosphere could be made and were to give results significantly below the minimum profile of Fig. 2 the assumed $\mathrm{CO}_{2}$ dissociation rate would be seriously questioned. Such a result would suggest that the apparent $\mathrm{CO}_{2}$ absorption continua above the $903 \AA$ ionization threshold are partially made up of unresolved band systems which do not lead to appreciable dissociation. This conclusion might shed new light on the low atomic oxygen concentration in the Martian atmosphere.

Acknowledgement-This work was supported by National Aeronautics and Space Administration Grant NASr-54 (03) and National Science Foundation Grant GA-1025.

\section{REFERENCES}

BoLIN, B. and KeELING, C. D. (1963). J. geophys. Res. 68, 3899.

CAIRNS, R. B. and SAMSON, J. A. R. (1965). J. geophys. Res. 70, 99.

Chapman, S. and Cowling, T. G. (1939). The Mathematical Theory of Non-Uniform Gases. University

Press, Cambridge.

Colgrove, F. D., Hanson, W. B. and Johnson, F. S. (1965). J. geophys. Res. 70, 4931.

Colgrove, F. D., Johnson, F. S. and Hanson, W. B. (1966). J. geophys. Res. 71, 2227.

Curtis, A. R. and Goody, R. M. (1956). Proc. R. Soc. Lond. A236, 193.

GuLd, E. (1909). Proc. R. Soc. Lond. A82, 43.

Gudiksen, P. H., Fairhall, A. W. and ReEd, R. H. (1968). J. geophys. Res. 73, 4461.

HesstVedt, E. (1967). Geofys. Publr 27, 1.

Hinteregger, H. E., Hall, L. A. and Schmidtke, G. (1965). Space Research V. North-Holland, Amsterdam.

Jornson, F. S. and WiLkIns, E. M. (1965). J. geophys. Res. 70, 1281.

Johnson, F. S. (1968). Physical Processes Influencing the Chemistry of Planetary Atmospheres. 4th Western Regional Mtg, Am. chem. Soc., San Francisco.

KaplaN, L. D. (1959). J. opt. Soc. Am. 49, 1004.

Kaufman, F. (1968). Symp. on Laboratory Measurements of Aeronomic Interest. I.A.G.A. Toronto.

LetTau, H. (1951). Diffusion in the upper atmosphere. Compendium of Meteorology (Ed. T. F. Malone), p. 320. Waverly Press, Baltimore.

Nakata, R. S., Watanabe, K. and Matsunaga, F. M. (1965). Sci. Light 14, 54.

OLIVERo, J. J. (1970). A study of the thermal structure of the mesosphere and lower thermosphere. Ph.D Dissertation, University of Michigan.

Robinson, E. and RobBins, R. C. (1967). Sources, abundance, and fate of gaseous atmospheric pollutants. Final Rep., SRI Project PR-6755, 123 pp.

Rommand, J. (1966). NASA CR-371, A Congeries of Absorption Cross Sections for Wavelengths Less Than $3000 \mathrm{~A}$ (Eds. J. O. Sullivan and A. C. Holland), p. 50. Clearinghouse for Federal Scientific and Technical Information. Springfield, Va.

Thompson, B. A., Harteck, P. and ReEves, R. R., JR. (1963). J. geophys. Res. 68, 6431.

\section{APPENDIX}

The $\mathrm{CO}_{2}$ and $\mathrm{CO}$ distributions are described by the following equations, respectively:

$$
\begin{gathered}
\frac{\mathrm{d} \zeta}{\mathrm{d} z}=\frac{\mathrm{d}}{\mathrm{d} z} \frac{\gamma_{2}}{\tilde{\gamma}_{2}}=-\frac{\varphi_{\mathrm{dLt}}+\varphi_{\mathrm{IOA}}}{\bar{\gamma}_{2} N\left(D_{2}+K_{T}\right)} \\
\frac{\mathrm{d} \gamma_{1}}{\mathrm{~d} z}=\frac{\varphi_{\mathrm{d} 1 \mathrm{~s}}}{N\left(D_{1}+K_{T}\right)}-\frac{\gamma_{1} D_{1}}{\left(D_{1}+K_{T}\right)} \frac{H-H_{1}}{H H_{1}}
\end{gathered}
$$

where: $\zeta=\gamma_{2} / \tilde{\gamma}_{2}$

$\gamma_{2}$ is the actual $\mathrm{CO}_{2}$ mixing ratio

$\tilde{\gamma}_{3}$ is the zero flux $\mathrm{CO}_{2}$ mixing ratio

$$
=\bar{\gamma}_{\mathrm{a}}^{0} \exp \left\{-\int_{z_{0}}^{z} \frac{D_{\mathrm{z}}}{\left(D_{2}+K_{z}\right)} \frac{\left(H-H_{2}\right)}{H H_{z}} \mathrm{~d} z\right\}
$$


$\varphi_{\mathrm{d} 1 \mathrm{~s}}$ is the photochemical induced flux from dissociation

$$
=\int_{z}^{\infty} \bar{\gamma}_{\mathrm{a}} N \zeta J_{\mathrm{d} 1 \mathrm{~s}} \mathrm{~d} z
$$

$J_{\mathrm{ats}}$ is the dissociation rate, per molecule

$\varphi_{\text {in }}$ is the photochemical induced fux from ionization

$$
=\int_{z}^{\infty} \tilde{\gamma}_{2} N \zeta J_{\text {ion }} \mathrm{d} z
$$

$f_{\text {toun }}$ is the ionization rate, per molecule

$N$ is the total number density

$D_{2}$ is the effective molecular diffusion coefficient for $\mathrm{CO}_{2}$

$K_{x}$ is the eddy diffusion coefficient

$H$ is the atmospheric scale height

$\mathrm{H}_{2}$ is the specific scale height for $\mathrm{CO}_{2}$

$\gamma_{1}$ is the actual Co mixing ratio

$D_{1}$ is the effective molecular diffusion coefficient for $\mathrm{CO}$

$H_{1}$ is the specific scale height for $\mathrm{CO}$.

Both equations were integrated between the tropopause ( $12 \mathrm{~km})$ and the arbitrary upper boundary at $200 \mathrm{~km}$ for each of the combinations of mixing and recombination. The following boundary conditions were employed:
(a) $\gamma_{2}^{0}=3.145 \times 10^{-4}$ at $z=12 \mathrm{~km}$.
(b) $\gamma_{1}^{0}=1.0 \times 10^{-7}$ at $z=12 \mathrm{~km}$. 